\title{
Sustaining the brand idea in electronic environments
}

\section{Tobias Kollmann and Christina Suckow*}

Department of Economics

University of Duisburg-Essen

Universitätsstr. 9, 45141 Essen, Germany

E-mail: tobias.kollmann@uni-due.de

E-mail: christina.suckow@uni-due.de

*Corresponding author

\begin{abstract}
In addition to the functional value of a brand, the academic branding literature also emphasises the symbolic function of a brand. The importance of emotional values is often stressed by the necessity to create strong customer-brand relationships for building brand equity. Since the brand is a universal concept regardless of its setting, the need for achieving emotional attachment also holds for e-brands. In the upcoming e-branding literature, however, this aspect of emotional bonding is often neglected. The paper analyses how the electronic environment has an influence on the affectivity of brands to show what challenges companies have to overcome in order to successfully build emotional e-brands.
\end{abstract}

Keywords: e-branding; emotions; internet; brand equity.

Reference to this paper should be made as follows: Kollmann, T. and Suckow, C. (2008) 'Sustaining the brand idea in electronic environments', Int. J. Business Environment, Vol. 2, No. 2, pp.153-167.

Biographical notes: Dr. Tobias Kollmann is a Professor of Business Administration at the University of Duisburg-Essen, Germany. Since 2005 he has held the Chair of E-business and E-entrepreneurship at the University of Duisburg-Essen, where he focuses particularly on questions of business venturing and business development in the field of the net economy.

Christina Suckow is a doctoral candidate and Researcher at the Chair of E-business and E-entrepreneurship, University of Duisburg-Essen. Her academic interests are online marketing and e-branding. She is currently completing her dissertation on e-branding.

\section{Introduction}

The increasing competition in all kinds of markets and the growing fight for customer attention make the concept of brands an important element in today's business (Kapferer, 2004). During the last decade, a vast amount of branding papers was published, which discuss the multiple facets of branding and emphasise its importance in organisational practice (Hulberg, 2006). Although the brand's practical relevance in traditional markets 
is doubtless, a myriad of definitions and concepts have emerged that try to grasp the phenomenon of branding and the effects different contexts have on the mechanisms behind it. The internet, however, as a rapidly expanding medium, serves as a special kind of environmental context, which has not been researched extensively until today. Although some authors argue that branding will become irrelevant on the web (Sinha, 2000), others strongly support the notion of e-brands as key to e-business success (Carpenter, 2000). By potentially achieving financial goodwill, strong e-brands become important drivers of company performance, as the many high-volume e-business takeovers recently demonstrate. Aside from some researchers who have tried to analyse the role brands play in electronic environments (Sawhney, 2005; Ibeh et al., 2005), relatively little empirical work has been done on e-branding (Rowley, 2004). Unfortunately, those works often neglect traditional, established branding concepts, instead arriving at creative new ideas and branding models that are detached from existing brand theory. Conversely, there is no reason to reject the branding idea that evolved in consumer goods markets in other environments (Ward et al., 1999, p.86).

The main goal behind the idea of traditional branding is to create an emotional brand that ties the customer to the brand (Keller, 2003; Gobé, 2001; Bhat and Reddy, 1998). Especially as functional product attributes do not adequately discriminate between products anymore, the emotional value added is decisive for a differentiated positioning of the brand on the target market. Thus, functional capabilities must be replaced by symbolic, emotional values when it comes to understanding the function of brands (De Chernatony and McDonald, 2003). The growing strategic significance of emotions in the brand-building process has found much attention in recent branding papers (Watzlawick et al., 1968; Heath et al., 2006). Many of the attempts to explain the process from a more psychological customer-centred perspective are consolidated by Keller's (1993; 2003) customer-based brand equity concept. In general, brand equity is about the customer's perception of attractiveness, engagement and bonding to the brand in terms of customer-brand relationships (Martesen and Grønholdt, 2004). In Keller's understanding, the creation of emotions is one of the fundamental steps in building brand equity. Accordingly, strong brand relationships can only be achieved by strong and positive brand-related feelings and a strong and positive attitude towards the brand (Keller, 2003). Keeping the importance of emotions in this theoretical model in mind, it seems surprising that there are only rare attempts of online brands to create affective states with the consumer. In fact, not only the e-branding practice but also e-branding research is dominated by a rather unemotional perspective on branding. Research in e-branding, for example, considers aspects like the dynamism, actuality and content quality of the website or consistency in terms of visual cues and content (Ind and Riondino, 2001). Without a doubt, these are important facets of e-branding, but the very core of the branding idea is still the creation of emotions.

In this paper we make an attempt to address possible reasons for the undervaluation of emotions in terms of e-brands in order to find ways to overcome the barriers to emotional branding on the web. We first start with some general and widely accepted brand research findings that support our argument for creating emotions as the core idea of branding. We then consider the specific conditions that the electronic environment reveals with regard to e-branding, leading to a discussion of the challenges and opportunities for companies to emotionalise their brands on the web. 


\section{The branding idea}

By attempting to summarise the myriad of branding definitions, we define a brand as the subjective "perception of an integrated bundle of information and experiences" (Duncan, 2002, p.13), making the brand something that lives entirely in the mind of the beholder (Upshaw, 1995). The subjective nature of a brand is often reflected by the concept of brand image, which is the subjective perception a customer has of a brand's identity (Nandan, 2005). Brand identity is the company's self-perception of the brand, which can be interpreted on two distinct levels: the tactical view of the visual identity and the strategic view of organisational behaviour and culture that effect performance (Da Camara, 2006). The strategic view of identity is based and conceptualised on some central components, such as corporate brand vision and culture, which drive positioning, personality and subsequent relationships (De Chernatony, 1999). In any kind of communication, the perception of the brand identity must be fine-tuned (actively controlled for) in order to create the desired brand image with the audience. This requires a balanced approach to brand building by relating externally oriented indicators (e.g., reputation/image) to internal components of brand identity in order to ensure an optimal match between identity and image. According to De Chernatony (1999):

"identity is about the ethos, aims and values that create a sense of individuality differentiating the brand, i.e., firm centred, while image is a holistic impression of the relative position of a brand among its perceived competitors, i.e., customer centred." (p.165)

Keller's visualisation of the brand equity-building process (see Figure 1) is the so-called customer-based brand equity pyramid (Keller, 1993; 2003). This pyramid summarises the mechanisms that lie behind the identity-driven brand-building conceptualisation and explains the role brand image and emotions play in a professional branding approach. Based on the perceived brand image (e.g., the individual's interpretation of the communicated brand promise and identity), customers develop some brand-related expectations, not only on how the product/brand will perform (e.g., functional product features), but also on how the emotional value added will potentially provide a unique shopping experience. The company is required to formulate a brand promise, which anticipates the customers' current and future needs both in functional as well as symbolic terms (Ward et al., 1999). This is especially important in the sense that the brand promise must be appealing enough to potential customers to create interest in engaging with the brand. In case of actual product use, any negative deviation from the promised value will obviously lead to unsatisfied and disappointed customers, who will not be willing to further engage in any kind of brand relationship. Thus, only if the created expectations (related to the functional and emotional value) are met will customers be willing to form a strong and positive attitude towards the brand. In combination with the aroused emotions, a favourable and strong attitude may eventually evolve into true brand commitment (Goodchild and Callow, 2001; Martesen and Grønholdt, 2004). In terms of customer-brand relationships, true brand commitment is stronger than pure behavioural loyalty, which is based on habitual buying decisions (Fournier, 1998). As Odekerken-Schröder (1999) pointed out, loyalty refers to repeat patronage, whereas commitment denotes affective preferences and takes into account the actual behaviour's antecedents. To achieve affective preference, the promised value cannot be narrowly 
defined in functional terms, which potentially leads to behavioural loyalty, but must as well be defined in emotional terms, which leads to attitudinal commitment (Ward et al., 1999).

Figure 1 The customer-based brand equity pyramid

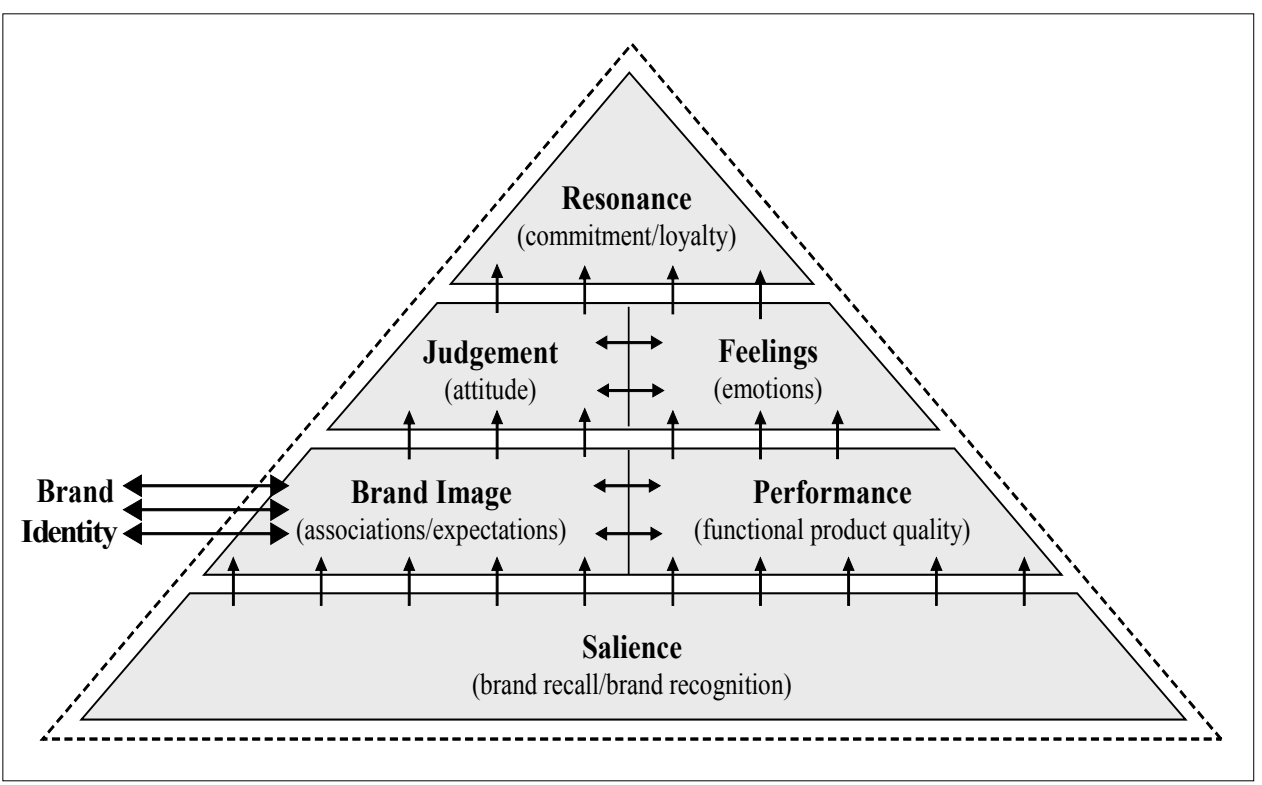

Source: According to Keller (2003, p.76)

As research on brand relationships shows, brand commitment represents the long-term orientation (e.g., the psychological attachment) towards the relationship. Blackston (1992) was among the first who identified an overt connection between emotions and relationships. He sees customer-brand relationships as a complex cognitive, affective and behavioural process. This means that rational and emotional processing are not two distinct concepts that lead to different behavioural outcomes; instead they are intertwined concepts that both influence individual behaviour (Gordon, 2006). Nevertheless, it is assumed that emotions tend to exert greater influence on customer-brand relationships (Heath et al., 2006). Although emotions are a strong element in relationship building, the rational aspects in terms of the functional quality of products are not at all dispensable. According to means-end theory (Gutman, 1982), there should be a particular set of functionally distinct capabilities that distinguishes one brand from another. Functional quality is rather a precondition for having a brand at all, but not a guarantee for branding success. Especially in technical markets, branding efforts often still revolve around product features and performance, because innovation and product advancements are wrongly understood as drivers of competitive advantage (for a discussion about this problem, see Sawhney, 2005). The lack of utilising emotional aspects with regard to branding matters is a phenomenon particularly observable at technology-driven, electronic markets. 
The circumstances that prevail in electronic markets are analysed in the next section in order to understand the phenomenon of e-branding in general. Subsequently, we discuss the characteristics of different web features and their relevance to emotional e-branding, followed by a description of the potential challenges that have to be overcome in order to arrive at a successful emotionalisation of an e-brand. As the field of emotional branding at the web is relatively new to academic research, the following sections should be seen as an attempt to highlight the issues that have to be considered with respect to the risks and chances of emotional branding at the web to initiate future research and to guide practical implementation.

\section{Electronic environments}

Building a sustainable brand often requires investing considerable time and money into positioning the brand on the desired market. In this respect, Shapiro (2005) claims that the frame of reference is a strategic tool that is all too often overlooked when it comes to the question of positioning a brand on the approached market. The need to consider the internet as a special frame of reference is closely related to its specific conditions. Those conditions include, for example, the increased information capacity of websites, the use of multimedia applications, the transparency of markets, global reach and the virtualisation of business processes. Therefore, brands are not unaffected by the environmental framework in which they compete. However, the internet will not affect all brands in the same way, because the relative importance of branding depends on the type of product being sold (Chen, 2001). Some marketing studies have demonstrated that buying patterns are often quite different for different types of products and customers and that nonrational factors such as emotional attachment and social desirability can strongly influence purchasing decisions (Beatty and Smith, 1987; Urbany et al., 1989).

As online environments are, by their nature, information-based service environments (Rowley, 2004), the urge for creating an emotional attachment that influences decision-making seems to be of secondary importance. In fact, there are still misconceptions about the relevance of branding in general, for example, that branding is only relevant when decisions are 'irrational' or 'emotional'. Although this might be true to some degree, this claim does not hold in markets where customers are highly sophisticated and strongly involved in decision-making (Ward et al., 1999, p.86). While in many technical-related decision-making processes, the evaluation of objective performance data is indeed relevant, branding success in electronic business environments is only achieved by providing an emotional brand experience that creates trust and sympathy and enduring customer-brand relationships in order to compete at a higher level. Performance competitiveness on the web is generally a short-sighted endeavour, since product features and performance are easily overhauled and leapfrogged by competitors. As Sawhney (2005) says, it is a "competitive rat race with no winners" (p.201). It is just a matter of time before the superior performance of one company is caught up with by the new ideas and innovations of competitors. Companies on the web must find other ways to differentiate themselves from competitors (Sawhney, 2005). Connecting the brand to emotional values overcomes the inherent constraints of product competitiveness. As almost all e-products relate to the processing of information in some way (which supports the notion of information being the competitive factor on the web), 
it must be clear that e-brands only add value to the customer if they process information on a high-quality level. Since information is a rather fast-changing variable in the electronic business environment and the quality of delivering information is thus strongly characterised by continuous change, branding is the balancing variable that is about consistency and continuity in delivering its promised value. The brand can be a valuable anchor of stability amid the change, uncertainty and confusion that is so pervasive in electronic markets (Sawhney, 2005).

Although some years ago, the lack of developing a structured brand idea in many dot.com companies made the brand a fairly underused and underrecognised resource among such companies (Ind and Riondino, 2001), the brand nowadays has evolved into a valued company asset that receives increasing attention from marketers and managers. However, technology firms still find it difficult to accept the importance of brand building and many e-business companies still believe that success in electronic markets is driven by technological innovation, product feature enhancement and improving price performance (Lambin, 1996). To be successful, brands must not only satisfy functional needs; more importantly, they must also satisfy emotional needs (Bhat and Reddy, 1998). Defining an attractive and unique brand positioning on the market requires brand managers to combine both functional and symbolic values (De Chernatony, 1999). The difficulties of already sustaining functional values in the short run result in a growing importance of emotional values, which should sustain competitive advantage in the long run (Goodyear, 1996).

The request for emotional branding activities of information-intense products splits the academic discussion about e-branding into two opposing schools of thought. Some researchers predict the end of brand management in electronic markets, at least in the way it can be found in traditional markets. Sealy (1999), for example, argues that traditional brand management is ineffective in today's e-markets, because of the wide range of new media and new techniques like interactivity and individuality. Particularly, information transparency, through the widespread availability of information about products, prices and competitors, is seen by some as posing a threat to brands (Chen, 2001). Some authors argue that branding will - despite the plenitude of information - become irrelevant on the web since intelligent agents and search engines are able to help handle this information overload (Rowley, 2004). According to Sinha (2000), the internet even represents the biggest threat to a firm's ability to brand its products since the extraction of price premiums is no longer possible in e-markets. In fact, he claims that the internet encourages highly rational shopping behaviours because online shoppers make dispassionate comparisons of prices and features.

\footnotetext{
"And although surfers' increasing use of multimedia will give companies new opportunities to provide sensory cues on-line, the solitary, information rich nature of web shopping will continue to encourage people to make decisions based on reason rather than emotion." (Sinha, 2000, p.48)
}

On the other hand, many researchers see e-branding as key to the success of business on the internet (Carpenter, 2000). They claim that the internet is more a revolution of communication than a revolution of technology and branding is therefore more important than ever (McGovern, 1999). E-branding must especially serve as a means to readdress the skewed balance of power of e-markets in favour of the "increasingly fickle and less loyal online customer" (Ibeh et al., 2005, p.356). Limited cognitive resources and time make customers apply e-brands as mental shortcuts in order to handle the use of 
information processing capacity and time (Einwiller et al., 2000). E-brands as shortcuts or navigation facilitators can thus play an important role in consumer behaviour on the web. In addition, the unstable and uncertain environment of the internet and the fact that there is a fundamental lack of faith between businesses and customers on the web (Hoffmann et al., 1999) necessitate that brands function as reference points for customers to create trust. Berry (2000), for example, suggests that trust is even more necessary on the web due to its virtual character, which prohibits any physical contact with the product/brand itself. Jevons and Gabbott (2000) even claim that trust and product quality alike must be at a satisfactory level even before a brand is included in a customer's consideration set at all. In order to build a strong brand equity, trust and product quality must be enriched with brand-related feelings that emotionally connect the customer and the brand.

\section{The influence of web features on emotional branding}

As internet practice shows, branding on the web is definitely existent and, with regard to today's e-brands, in some cases even very successful (Amazon, Google, eBay). The discussion about the usefulness of branding on the web can therefore not be a question of 'yes' or 'no'; it is a question of the right implementation. As research has shown, the simple replication of offline marketing efforts to online environments is not adequate (Meyers and Gerstmann, 2001), since the internet's unique characteristics have implications for developing and managing brands (De Chernatony, 2001). This does not imply that the principles of branding in traditional markets are not relevant in electronic environments (Porter, 2001), as the brand is a universal concept regardless of its setting. What changes online is the enactment of the brand (De Chernatony and Christodoulides, 2004). The use of new technology to market brands enables companies to engage in branding activities not previously feasible (Godek and Yates, 2005). Bezjian-Avery et al. (1998) suggest that the internet is able to fundamentally change relationships between consumers and brands by opening up the potential for new forms of dialogue. The ways in which brand equity is created online must therefore be different from traditional offline contexts (Christodoulides et al., 2006). To thoroughly analyse the influence of the web on emotional branding, the internet's unique characteristics as well as its inherent features have to be examined concerning their potential to modify emotional branding practices on the web as compared to traditional settings.

\subsection{Interactivity}

First of all, the internet allows for real-time bilateral and multilateral communication and interaction between all kinds of users (Peterson et al., 1997). The web environment enables customers to turn from passive receivers of marketing communications to active participants in the communication process (Duncan and Moriarty, 1998). The interactive nature of the internet allows for two-way, real-time communications between firms and consumers (Hoffmann and Novak, 1996). As the interaction between two partners is one of the critical conditions for relationship formation (Bersheid and Reis, 1998), the use of interactive features at the website (e.g., online-games, chats) can strengthen the consumer-brand relationship. Park et al. (2005) therefore suggest that "strong 
customer-brand relationships are likely to be more common in the online setting than in the offline setting" (p.381). Interactivity is also able to increase the general involvement of customers, thereby possibly increasing the emotional attachment to the brand. Involvement is defined as "an internal state variable that indicates the amount of arousal, interest, or drive evoked by a stimulus" (Beatty and Smith, 1987, p.88). Decision-making processes and the search for information are both affected by the level of involvement (Kapferer and Laurent, 1985). Highly involved customers are strongly motivated to launch cognitive processes to evaluate the brand and to initiate emotional responses (Foxman et al., 1990).

\subsection{Selectivity}

Although interactivity comprises many opportunities to obtain some emotional engagement of the customer, it presupposes the prior activation of the customer to find the brand's website. In this respect, the selectivity with which customers process information is a challenge as well as an opportunity to e-branding. Due to the information richness on the web, customers only react to stimuli that are subjectively valued to be relevant for their decision-making process (Scherer et al., 2001; appraisal theory). ${ }^{1}$ The risk of not being considered in the selection process is of course high if the brand fails to draw the customer's attention properly with relevant information. On the other hand, if attention is drawn, the self-selected willingness to engage with the brand leaves much room for implementing emotional branding activities. As an attention-getter and central contact point, the website is the needle's eye of any e-branding activity. Many e-businesses have already recognised the important function of the brand's website, but they still put much effort into the sole attraction of customers by spending huge amounts on online marketing campaigns (banner advertising, search engine optimisation, link lists, etc.). Only few brands have understood that attention is only a sine qua non but not a sufficient condition for successful, emotional branding.

\subsection{Individuality}

According to appraisal theory, emotions are created by the subjective appraisal of events (Scherer et al., 2001). The individual appraisal is based on cognitive processes in which individually stored information in the memory is activated and used for the evaluation of the incoming stimuli (Nyer, 1997; Watson and Spence, 2007). In order to elicit the customer's emotions, it is therefore necessary to find stimuli which are cognitively processed in such a way that they instantly lead to the activation of the customer's individual pattern of associations, which in turn can function as an internal trigger of emotions. The individuality of associations levers the creation of emotions and makes success dependent on discovering and understanding the stimuli that elicit emotions according to the individual context of the customer. To achieve this, knowledge about customers and their needs, preferences and likes are inevitable. Compared to traditional business environments, where the gathering of customer-relevant data is expensive and complex, the internet has many opportunities to easily collect important customer data. The digitalisation of information is a web characteristic that not only enables the automatic storage of information but also the processing of data to the special needs of the business. In this way, companies can easily learn from any interaction between customer and brand. In the context of e-branding, this characteristic allows for the 
individualisation of any customer-brand relationship at a relatively low cost and theoretically opens the door for the successful implementation of emotional branding strategies. The more data the customer leaves, the better any emotional branding activity can be tailored to the customer, potentially leading to a higher success rate in terms of emotional connectivity between brand and customer. The challenge companies face here is the task of purposefully using collected data. Too many of them have no precise branding concepts, which include clear principles and guidelines about how to handle customer-relevant data (Ind and Riondino, 2001). The purposeful utilisation of customer data must always be closely connected to the brand identity that is pursued in order to fortify the stability and continuity of any branding activity.

\subsection{Multimediality}

Another web feature that is probably the most valuable concern for emotional branding is the deployment of multimedia applications. Electronic environments offer the possibility of easily combining different types of media onto the website. Multimedia may be defined as "multiple perceptual representation media such as speech, music, text, graphic, still, animation and video, used in an integrated manner" (Hoogeveen, 1997, p.151). By integrating different media for branding purposes, the internet has the ability to provide perceptual experiences that are far superior to those from other media (Peterson et al., 1997). This is generally based on the assumption that different types of media increase the amount of cognitive cues (Severin, 1967). By using cues from different modalities simultaneously, they either facilitate information processing, thereby yielding increased effectiveness, or they interfere with each other through the incompatibility of information, leading to mental conflicts (Miller, 1957). Although the general advantage of having multiple communication cues is recognised, there are also researchers who point to the weaknesses of multimedia. For example, some state that the limited capacity of information processing may lead to cognitive overload and therefore the decreasing effectiveness of multimedia (Lang, 2000; Jo and Kim, 2003). In sum, using multimedia applications on a brand's website only supports the general branding purpose when the different cues (different types of media) are coordinated in such a manner that they facilitate information processing rather than confuse the customer by providing contradicting message elements. This integration of brand communication is necessary for establishing a clear and undiffused brand image to the customer. To go one step further, the emotional connectivity between customer and brand can be reached by strongly integrated and coordinated multimedia appliances that do not only provide a clear brand image but also appeal to the customer's emotional expectations, raised by the image in a way that makes the elicitation of emotions likely. This requires the close combination and consolidation of multimedia applications with the above discussed web features, like individuality, selectivity and interactivity, and the tight alignment of those features with the brand's identity or with the desired brand image. Multimedia per se (like the other features) is probably a feature that enhances the positive brand image due to its innovative utility (Hoogeveen, 1997), but in order to support the emotional branding process, the web features must by no means be viewed in isolation. Exhausting the potential of web features for the creation of brand-related emotions is thus a question of integration. 


\section{Challenges to overcome}

Although some researches are still arguing about whether branding on the web is necessary at all, the majority recognise and emphasise the importance of the concept of brands on the web. The creation of a powerful and sustained e-brand with the necessary emotional appeal requires overcoming five main challenges.

\section{Change the managerial attitude}

The main problem in this context is the lack of acceptance of the branding concept in organisational practice. While researchers are already convinced that branding on the web is a must, practitioners are not. Most managers think that competition takes place on the product level and since the internet is an information-based service environment, the quest for building an emotion-laden e-brand may appear to be of secondary nature. What most of them forget is that building strong brands offers an attractive avenue for internet firms to insulate themselves from competition. The first challenge to overcome before a successful e-branding strategy can be implemented is a general change in managerial attitude from product centric to brand/promise centric (Ward et al., 1999). By pursuing the brand-centric attitude, managers recognise that good (electronic) product performance is the price of admission to the competitive field on the web, but not the warranty of staying ahead. What matters is the provision of emotional added value to the customer on top of functional values.

2 Give customers a reason to come back

Since the internet changes the role of the customer from a passive to an active participant of any communication process, e-brands generally face the difficulty of getting the necessary attention. The selectivity of customers and the information richness of the internet make it difficult for companies to be selected by the right target group. Although this fear is justified, the problem is not so much the attraction of customers but their preservation to make them return to the website. Once the customer visits the website, his/her attention level tends to be higher than for any other medium. Companies need to put more effort into making the customers return by using the increased attention. Having this in mind, just placing banners and links on external websites to make the potential customer find the brand's website is not enough. In this respect, the convergence of branding activities on one website is a chance for those brands that are able to offer reasons to come back, but a risk for those that are not. This is not only a question of the functional but also of the emotional superiority of the e-brand compared to competitors.

\section{Use data more purposefully}

The digitalisation of information on the web allows internet firms to save, transform and use accrued customer data for their branding activities. Since a big bulk of customer data can be automatically generated, the challenge is not the gathering of information; it is the use of information in a brand-related, strategic manner. This means that there need to be clear guidelines on how data is processed and transformed into valuable and useful information about customers and their beliefs, attitudes, needs and wants. In order to be relevant for the implementation of 
emotional branding strategies, the rules and specifications for data usage must be clearly formulated in terms of branding goals, making the use of digital information more purposeful.

\section{Create individual emotional appeals}

Since the most valuable customer data are accumulated during interactive communication processes between customer and brand, interactivity is certainly a web feature that facilitates the implementation of emotional branding activities. The formation of strong customer brand relationships is very much dependent on the company's ability to anticipate the customer's needs. This is most easily done by analysing customer data. Nevertheless, knowledge about customers is only a prerequisite for building strong brands. The internet provides enough room for beneficial applications of customer knowledge, for example, in the form of one-to-one communication and individual product offerings. To create emotional bonds to the brand, customer knowledge must also be used to create emotional customer resonance. The challenge is to emotionally appeal to every single customer by simultaneously pursuing the development of a strong brand identity.

\section{Suit the branding to the medium}

Ind and Riondino (2001) identified two major problems that brand managers of traditional brands face today when they bring their brand online. Some of them think that a new identity for the web must be created, whereas others think that they just have to stick to their identity without making any adjustments. The best strategy, though, is to do both: sticking to the identity and your brand promise and values, but adjusting the identity to a level where it best suits the medium. These problems do not occur for purely web-based brands, because they have the opportunity to build their web identity free of any brand-related liabilities. Thus, creating emotions can be part of a structured and planned brand identity concept, reflecting the characteristic of the medium. One of the biggest challenges of creating an emotional e-brand is thus the integration of different web characteristics to the brand identity idea. There are two aspects that are of concern: First, the brand story on the internet must be embedded in the vantages of the web characteristics since emotional branding activities must be suited to the medium. Second, it is helpful to derive the brand story from the web's characteristics up to a certain degree, because the reflection of the medium's specific characteristics in the brand story makes the brand more authentic, which accelerates the likelihood of creating an emotional response.

\section{Conclusion}

This paper proposes that emotions are a fundamental element of the branding process in electronic environments. The traditional branding literature already recognises the value of emotions within the branding process, but the e-branding literature is still focusing on functional product superiority and the utilisation of web features. The need for creating emotions on the web is thus not yet evident. As competition gets fiercer and the request for more customer orientation on the web gets louder, it is only a question of time when emotions gain the same appropriate advertence in e-branding practice as it has in 
traditional markets. By discussing the general effects that business environments have on the branding framework, special emphasis was given to the internet as one business environment that fundamentally impacts the concept of brand. In order to show how the request for more emotions on the web could possibly be implemented, we analysed some special web characteristics (e.g., interactivity, selectivity, individuality and multimediality) with respect to their ability to create emotions. To facilitate the emotional e-branding approach, there are some major challenges that must be overcome before an emotional branding strategy can be successful. First of all, top management must start to recognise the growing importance of emotions within the branding process. After achieving a general change in managerial attitude, the sophistication of branding practices in the context of electronic environments must take place. The most important implication the web has on branding is the selective attention of users towards accessible electronic information. Although the activation of customers in general is thus very important to increase the traffic to the website, the brand must give customers a good reason to come back. The data that is automatically gathered during every site visit must be used more purposefully. E-brands must use this data to implement interactivity and individuality not for the sake of creating an innovative reputation, but for the sake of creating an emotional bond between customer and brand. In this way, it seems important to provide an emotional appeal by suiting all branding activities to the medium without losing sight of the brand's identity. The challenge brand managers are facing with respect to the implementation of an emotional branding strategy is thus the tight pursuit of the brand's identity on the one hand and the simultaneous enhancement of flexible, individual customer-driven brand communication on the other hand. In other words, it is not the dilemma of doing one or the other; it is the chance of doing both at the same time, which traditional brands cannot.

To enhance the understanding of emotional e-branding, future research must provide practical insights into how to precisely implement an emotional e-branding strategy by identifying those factors that contribute more to the creation of emotions than others. It is important to understand the exact mechanisms in the customer's psyche that are responsible for triggering emotions before more accurate practical implications can be derived. For this purpose, it might be interesting to take a more psychological and sociological perspective on e-brands in future research. Insight from information processing or information integration theory, for example, may be extremely useful for understanding the exact processes that take place in the customer's mind when visiting the brand's website. Furthermore, empirical research, for example, in an experimental design framework, could provide a lot of insights concerning the value and contribution of different factors to the success of emotional arousal. The e-branding literature must thus allow for the open up to psychological and sociological theories that are able to explain the mechanisms of branding in the customer's head. By exploiting the plurality of empirical methodologies and by adding insights from other research disciplines, e-branding research could be accessed more comprehensively. 


\section{References}

Beatty, S.E. and Smith, S.M. (1987) 'External search effort - an investigation across several product categories', Journal of Consumer Research, Vol. 14, No. 1, pp.83-95.

Bersheid, E. and Reis, H.T. (1998) 'Attraction and close relationships', in D.T. Gilbert, S.T. Fiske and G. Lindzey (Eds.) The Handbook of Social Psychology, 4th ed., Boston: McGraw-Hill, pp.13-281.

Berry, L. (2000) 'Cultivating service brand equity', Journal of the Academy of Marketing Science, Vol. 28, No. 1, pp.128-137.

Bezjian-Avery, A., Calder, B. and Iacobucci, D. (1998) 'New media interactive advertising vs. traditional advertising', Journal of Advertising Research, Vol. 38, No. 4, pp.23-32.

Bhat, S. and Reddy, S.K. (1998) 'Symbolic and functional positioning of brands', Journal of Consumer Marketing, Vol. 15, No. 1, pp.32-43.

Blackston, M. (1992) 'Observations: building brand equity by managing the brand's relationships', Journal of Advertising Research, Vol. 32, No. 3, pp.79-83.

Carpenter, P. (2000) eBrands: Building an Internet Business at Breakneck Speed, Harvard: Harvard Business School Press Books.

Chen, S. (2001) 'Assessing the impact of the internet on brands', Journal of Brand Management, Vol. 8, Nos. 4-5, pp.288-302.

Christodoulides, G., De Chernatony, L. and Furrer, O. (2006) 'Conceptualising and measuring the equity of online brands', Journal of Marketing Management, Vol. 22, Nos. 7-8, pp.799-825.

Da Camara, N. (2006) 'Clear definitions in identity, image and reputation', Henley Manager Update, Vol. 18, No. 2, pp.9-17.

De Chernatony, L. (1999) 'Brand management through narrowing the gap between brand identity and brand reputation', Journal of Marketing Management, Vol. 15, pp.157-179.

De Chernatony, L. (2001) 'Succeeding with brands on the internet', Journal of Brand Management, Vol. 8, No. 3, pp.186-195.

De Chernatony, L. and Christodoulides, G. (2004) 'Taking the brand promise online: challenges and opportunities', Interactive Marketing, Vol. 5, No. 3, pp.238-251.

De Chernatony, L. and McDonald, M. (2003) Creating Powerful Brands - In Consumer, Service and Industrial Markets, 3rd ed., Oxford: Elsevier.

Duncan, T. (2002) IMC: Using Advertising and Promotion to Build Brands, New York: McGraw Hill.

Duncan, T. and Moriarty, S.E. (1998) 'A communication-based marketing model for managing relationships', Journal of Marketing, Vol. 62, No. 2, pp.1-13.

Einwiller, S., Geissler, U. and Will, M. (2000) 'Engendering trust in internet business using elements of corporate branding', in H.M. Chung (Ed.) Proceedings of the 2000 Americas Conference on Information Systems (AMCIS 2000), pp.733-739.

Fournier, S. (1998) 'Consumers and their brands: developing relationship theory in consumer research', Journal of Consumer Research, Vol. 24, No. 4, pp.343-373.

Foxman, E., Muehling, D. and Berger, P. (1990) 'An investigation of factors contributing to consumer brand confusion', Journal of Consumer Affairs, Vol. 24, No. 1, pp.170-189.

Gobé, M. (2001) Emotional Branding: The New Paradigm for Connecting Brands to People, New York: Allworth Press.

Godek, J. and Yates, J.F. (2005) 'Marketing to individual consumers online: the influence of perceived control', in C.P. Haugtvedt, K.A. Machleit and R.F. Yalch (Eds.) Online Consumer Psychology, London: Erlbaum.

Goodchild, J. and Callow, C. (2001) Brands: Visions and Values, Chichester: John Wiley \& Sons.

Goodyear, M. (1996) 'Divided by a common language: diversity and deception in the world of global marketing', Journal of the Market Research Society, Vol. 38, No. 2, pp.105-122. 
Gordon, W. (2006) 'What do consumers do emotionally with advertising?', Journal of Advertising Research, Vol. 46, No. 1, pp.2-10.

Gutman, J. (1982) 'A means-end chain model based on consumer categorization processes', Journal of Marketing, Vol. 46, No. 2, pp.60-72.

Heath, R., Brandt, D. and Nairn, A. (2006) 'Brand relationships: strengthened by emotion, weakened by attention', Journal of Advertising Research, Vol. 46, No. 4, pp.410-419.

Hoffman, D., Novak, T. and Peralta, M. (1999) 'Building consumer trust in online environments: the case for information privacy', Communications of the ACM, Vol. 42, No. 4, pp.80-85.

Hoffmann, D.L. and Novak, T.P. (1996) 'Marketing in hypermedia computer-mediated environments: conceptual foundations', Journal of Marketing, Vol. 60, No. 2, pp.50-68.

Hoogeveen, M. (1997) 'Toward a theory of the effectiveness of multimedia systems', International Journal of Human-Computer Interaction, Vol. 9, No. 2, pp.151-168.

Hulberg, J. (2006) 'Integrating corporate branding and sociological paradigms: a literature study', Journal of Brand Management, Vol. 14, Nos. 1-2, pp.60-73.

Ibeh, K.I.N., Luo, Y. and Dinnie, K. (2005) 'E-branding strategies of internet companies: some preliminary insights from the UK', Journal of Brand Management, Vol. 12, No. 5, pp.355-373.

Ind, N. and Riondino, M. (2001) 'Branding at the web: a real revolution?', Journal of Brand Management, Vol. 9, No. 1, pp.8-19.

Jevons, C. and Gabbott, M. (2000) 'Trust, brand equity and brand reality in internet business relationships: an interdisciplinary approach', Journal of Marketing Management, Vol. 16, No. 6, pp.619-634.

Jo, S. and Kim, Y. (2003) 'The effect of web characteristics on relationship building', Journal of Public Relations Research, Vol. 15, No. 3, pp.199-223.

Keller, K. (1993) 'Conceptualizing, measuring, and managing customer-based brand equity', Journal of Marketing, Vol. 57, No. 1, pp.1-22.

Keller, K.L. (2003) Building, Measuring, and Managing Brand Equity, 2nd ed., Upper Saddle River, NJ: Prentice Hall.

Kapferer, J. (2004) The New Strategic Brand Management, 3rd ed., London: Kogan Page, Sterling.

Kapferer, J. and Laurent, G. (1985) 'Consumer involvement profiles: a new practical approach to consumer involvement', Journal of Advertising Research, Vol. 25, No. 6, pp.48-56.

Lambin, J-J. (1996) Strategic Marketing Management, London: McGraw-Hill.

Lang, A. (2000) 'The limited capacity model of mediated message processing', Journal of Communication, Vol. 50, No. 1, pp.46-70.

Martesen, A. and Grønholdt, L. (2004) 'Building brand equity: a customer-based modelling approach', Journal of Management Systems, Vol. 16, No. 3, pp.37-51.

Meyers, H. and Gerstman, R. (2001) Branding at the Digital Age, New York: Palgrave.

McGovern, G. (1999) The Caring Economy: Business Principles for the New Digital Age, Dublin: Blackhall Publishing.

Miller, N.E. (1957) Graphic Communication and the Crisis in Education, Washington: National Education Association.

Nandan, S. (2005) 'An exploration of the brand identity-brand image linkage: a communications perspective', Journal of Brand Management, Vol. 12, No. 4, pp.264-278.

Nyer, P.U. (1997) 'A study of the relationships between cognitive appraisals and consumption emotions', Journal of the Academy of Marketing Science, Vol. 25, No. 4, pp.296-304.

Odekerken-Schröder, G.J. (1999) 'The role of the buyer in affecting buyer-seller relationship, empirical studies in a retail context', Doctoral dissertation, Maastricht, Universiteit Maastricht. 
Park, J., Lee, H. and Lee, H. (2005) 'Consumer relationships with an e-brand: implications for e-brand extensions', in C.P. Haugtvedt, K. Machleit and R. Yalch (Eds.) Online Consumer Psychology: Understanding and Influencing Consumer Behavior in the Virtual World, Mahwah, New Jersey, pp.379-400.

Peterson, R.A., Balasubramanian, S. and Bronnenberg, B.J. (1997) 'Exploring the implications of the internet for consumer marketing', Journal of the Academy of Marketing Science, Vol. 25, No. 4, pp.329-346.

Porter, M.E. (2001) 'Strategy and the internet', Harvard Business Review, Vol. 79, No. 3, pp.62-78.

Rowley, J. (2004) 'Online branding', Online Information Review, Vol. 28, No. 2, pp.131-138.

Sawhney, M. (2005) 'Branding in technology markets', in A.M. Tybout and P. Kotler (Eds.) Kellog on Branding, John Wiley \& Sons, pp.201-225.

Scherer, K., Schorr, A. and Johnstone, T. (2001) Appraisal Processes in Emotion: Theory, Methods, Research, Oxford: Oxford University Press.

Sealey, P. (1999) 'How e-commerce will trump brand management', Harvard Business Review, Vol. 77, No. 4, pp.171-176.

Severin, W.J. (1967) 'The effectiveness of relevant pictures in multiple-channel communications', Communication Review, Vol. 15, No. 4, pp.386-401.

Sinha, I. (2000) 'Cost transparency: the net's real threat to prices and brands', Harvard Business Review, Vol. 78, No. 2, pp.43-50.

Shapiro, M. (2005) 'Marketing leverage in the frame of reference', in A.M. Tybout and P. Kotler (Eds.) Kellog on Branding, John Wiley \& Sons, pp.283-288.

Upshaw, L.B. (1995) Building Brand Identity: A Strategy for Success in a Hostile Marketplace, New York: John Wiley.

Urbany, J., Dickson, P.R. and Wilkie, W.L. (1989) 'Buyer uncertainty and information search', Journal of Consumer Research, Vol. 16, No. 2, pp.208-215.

Ward, S., Light, L. and Goldstine, J. (1999) 'What high-tech managers need to know about brands', Harvard Business Review, Vol. 77, No. 4, pp.85-95.

Watson, L. and Spence, M.T. (2007) 'Causes and consequences of emotions on consumer behaviour: a review and integrative cognitive appraisal theory', European Journal of Marketing, Vol. 41, Nos. 5-6, pp.487-511.

Watzlawick, P., Bacelas, J.B. and Jackson, D.D. (1968) Pragmatics of Human Communication, London.

\section{Note}

1 The selective information processing is based on the individual's appraisal of an object or event and therefore subject to the so-called appraisal theories (for an overview read Scherer et al., 2001). 